\title{
Age-related macular degeneration and nutritional supplementation: a review of randomised controlled trials
}

\author{
Hannah Bartlett and Frank Eperjesi \\ Neurosciences Research Institute, School of Life and Health Sciences, Aston \\ University, Aston Triangle, Birmingham B4 7ET \\ bartlehe@aston.ac.uk
}

\begin{abstract}
Age-related macular degeneration (AMD) is the leading cause of severe vision loss in the developed world. The lack of effective treatment modalities, coupled with evidence supporting an oxidative pathogenesis, has increased interest in the potential preventative role of nutritional supplementation.
\end{abstract}

This article reviews seven randomised controlled trials (RCTs) that have investigated the role of nutritional supplementation in AMD. Three of these trials reported a positive effect of nutritional supplementation on AMD; the AgeRelated Eye Study (AREDS), the Lutein Antioxidant Supplementation Trial (LAST), and the oral zinc trial by Newsome et al. (1988). However, the oral zinc trial by Newsome et al. (1988) was unlikely to detect any difference between treatments smaller than $72 \%$, and the AREDS results were based on a subgroup of their study population. Lutein was considered for the AREDS formulation, but was not commercially available at that time. The findings of the LAST support a possible therapeutic role of lutein in AMD. 


\section{Keywords}

Age-related macular degeneration, randomised controlled trials, antioxidants, carotenoids, lutein

\section{Introduction}

Randomised controlled trials (RCTs) are considered to be the gold standard in clinical research (Gray, 1997; Huwiler-Muntener, 2002). The aim of this review is to evaluate RCTs that relate to the effect of nutritional supplements on agerelated macular degeneration (AMD). RCTs involve random assignment of participants into treatment and placebo groups. The advantage of trials of this type is the ability to reduce, by masking, the influence of confounding variables by random assignment of the treatment (intervention), and the ability to reduce bias or the possibility that any observed effect is due to other factors. The term 'double-masked' or 'double-blinded' refers to the fact that neither investigator nor participants know who is in the treatment or placebo group. In RCTs designed to investigate the effect of nutritional supplements, this is usually

achieved by coding of the tablet containers. At the end of the trial period the code is broken and the gathered data analysed.

In summary, any RCT will involve the following steps (Hulley et al., 2001):

1. Sample selection from the population

2. Baseline variables measured

3. Participants randomised

4. Interventions applied (one will be a placebo) 

5. Follow up of the cohort
6. Outcome variables measured
7. Results analysed

The role of nutritional supplementation in ocular health is of interest to eye care practitioners. Many have expressed a need for clearer guidance regarding the recommendation of supplements to their patients (Evans, 2002; Stainer, 2002). The increase in advertising and marketing of nutritional formulations has, in turn, increased awareness of the potential benefits of these supplements within the general population.

\section{Terminology of age-related macular degeneration}

The International Classification and Grading System for Age-Related Maculopathy (ARM) and Age-Related Macular Degeneration (AMD) has been developed in an attempt to standardise terminology (Bird et al., 1995):

ARM is characterised by soft, confluent drusen, areas of hyperpigmentation associated with drusen, areas of hypopigmentation of the RPE without any visibility of choroidal vessels associated with drusen (also known as 'early AMD').

AMD is a late stage of ARM and includes both non-exudative and exudative macular degeneration. 
In this article the terms ARM and AMD will be used according to this classification.

\section{Aetiogenesis of AMD}

AMD is the leading cause of blindness in the developed world (Klein et al., 1992; Klein et al., 1995; Evans and Wormald, 1996). Diet has been related to AMD as well as other chronic conditions such as hypertension and cardiovascular disease (Williams et al., 1971; Manson et al., 1991; Osilesi et al., 1991; Jacques, 1992a; Jacques, 1992b; Gey et al., 1993; Vitale et al., 1993; West et al., 1994).

\section{Oxidation hypothesis}

One hypothesis for the aetiology of AMD involves the breakdown of antioxidant systems within the retina. An antioxidant can be defined as 'any substance that when present at low concentrations compared to those of an oxidisable substrate, significantly delays or prevents oxidation' (Halliwell, 1999). In the retina, normal metabolic processes, as well as exposure to high-energy visible light generate potentially damaging, activated forms of oxygen (Eye Disease Case Control Study (EDCCS) Group, 1993) called free radicals. Free radicals are molecules that have one or more unpaired electrons and are produced via the process of oxidation. Normal aerobic metabolism produces free radicals such as superoxide, hydroxyl radicals, singlet oxygen radicals and hydrogen peroxide. Free radicals can initiate lipid peroxidation, which is thought to lead to

oxidative damage to DNA, protein and carbohydrate within cells (Curcio and 
Millican, 1999). The retina is particularly susceptible to damage via this process for several reasons:

1. Polyunsaturated fatty acids are abundant in the retina, particularly the macular region. They are found in photoreceptor outer membranes and are readily oxidised (Machlin and Bendich, 1987; Beardsley, 1991; Van der Hagen et al., 1993).

2. The retina is subjected to high levels of light exposure. Light (particularly blue light) is a strong oxidising agent. The simultaneous presence of light and oxygen promotes production of free radicals (Schalch, 1992).

3. Phagocytosis, which itself produces free radicals, occurs within the retinal pigment epithelium (RPE).

4. The retina is highly active metabolically and has a much higher blood flow than other tissues (Schalch, 1992).

The body has several defence mechanisms against the production of free radicals. The first involves antioxidant enzymes such as catalase and peroxidase (Sies, 1991). Other micronutrients such as selenium, zinc, manganese, and copper facilitate these antioxidant enzymes (Sies, 1991; Bressler and Bressler, 1995). The second involves antioxidant nutrients such as vitamin E (alpha-tocopherol) (Machlin, 1980; Fukuzawa and Gebicki, 1983; 
Ozawa et al., 1983; Burton et al., 1985; McCay, 1985), beta-carotene (Burton and Ingold, 1984a) and vitamin C (ascorbate) (Nishikimi, 1975; Bodannes and Chan, 1979; Bielski, 1982; Hemila et al., 1985; Sies, 1991). Other antioxidants believed to play a part in maintenance of ocular health include the carotenoids lutein and zeaxanthin (Snodderly et al., 1984). Further defence mechanisms include antioxidant compounds such as metallathionein, melanin, and glutathione, and DNA repair. Compartmentalisation is another defence mechanism and this involves the separation of reactive oxygen species (ROS) from cellular components that are susceptible to oxidative damage (Sies, 1991). Insufficient intake of dietary antioxidant vitamins and minerals can decrease the efficiency of the body's natural antioxidant systems and may allow cellular damage by free radicals (Machlin and Bendich, 1987; Pippenger et al., 1991).

Other factors in AMD pathogenesis have been proposed, such as the declining function of Bruch's membrane with age (Feeney-Burns and Ellersieck, 1985; Bird and Marshall, 1986; Chuang and Bird, 1988), vascular insufficiency (Klein 1999), and genetic predisposition (Hyman et al., 1983; Smith and Mitchell, 1998).

\section{Bruch's membrane deterioration}

As the conductivity of Bruch's membrane declines with age (Feeney-Burns and Ellersieck, 1985; Bird and Marshall, 1986; Chuang and Bird, 1988); the consequential impedance of fluid flow from the RPE towards the choroid results in RPE detachment. Geographic atrophy may result if there is a reduction in 
metabolic exchange between the choroid and the RPE. The material in Bruch's membrane may be derived from the RPE (Ishibashi et al., 1986; Sheraidah et al., 1993; Moore et al., 1995). Blockage of nutrition or proliferation of choroidal blood vessels under the retina caused by this thickening of Bruch's membrane, may initiate choroidal neovascularisation. These new blood vessels destroy structures around them as they grow (Silvestri, 1997).

\section{Vascular insufficiency}

Changes in choroidal circulation may effect the normal diffusion of substances and gasses across the RPE-Bruch's membrane complex and have been linked with development of AMD (Verhoeff and Grossman, 1937; Potts, 1966; Kornzweig, 1977; Bischoff and Flower, 1983; Pauleikhoff et al., 1990). Removal of waste materials and disruption the supply of metabolites and gasses to the neural retina is disturbed. Deterioration of the RPE may result from this build up of waste products. (Friedman et al., 1995).

\section{Genetics}

Several studies have shown that there is an increased risk of AMD with a positive family history (Hyman et al., 1983; Smith and Mitchell, 1998). A genetic basis for AMD is supported by the occurrence of the condition in families. Genes for other macular dystrophies such as Stargardt's macular dystrophy and Best's vitelliform macular dystrophy have been mapped to specific chromosomes (Stone et al., 1992; Kaplan et al., 1993; Stone et al., 1994; Zhang et al., 1994). AMD is a multifactorial condition and it is likely that 
those with an inherited predisposition for the condition will develop it only with exposure to appropriate environmental factors (Bird, 1996; Silvestri, 1997).

\section{Clinicopathogenesis of AMD}

The first indication that the metabolic state of the normal, healthy retina has been altered can be seen as deposition of metabolic debris between the basement membrane of the RPE and Bruch's membrane. This accumulation of metabolic debris occurs in the senescent RPE and involves remnants of incomplete degradation from the phagocytosis of rod and cone cell membranes. Photoreceptor outer segments that are not digested in the lysosomes of RPE remain in the RPE cells as highly oxidised lipid material (lipofuscin) (Curcio and Millican, 1999). Part of the accumulation of lipid material on the inner collagenous layer of Bruch's membrane (Pauleikhoff et al., 1990) is clinically visualised as large drusen (Curcio and Millican, 1999), eventually leading to a drusenoid pigment epithelial detachment (PED). Inflammatory cells are thought to invade the drusenoid PED, leading the way to choroidal neovascularisation (Algvere and Seregard, 2002).

\section{Inclusion criteria for review studies}

Type of study

Randomised controlled trial comparing nutritional supplementation with a control.

Type of intervention
Any antioxidant vitamin or mineral, alone or in combination. The vitamins or minerals have antioxidant properties themselves, or are a 
component of an antioxidant enzyme within the retina.

A literature search was carried out on Web of Science and PubMed using the terms, 'age-related macular degeneration', 'macular degeneration', 'randomised controlled trial', 'controlled trial', 'supplementation', 'antioxidant', 'carotenoids', 'lutein'. The reference sections of those papers located in this way were then searched for other relevant studies.

RCTs included in this review are shown in table 1, and the nutrient amounts included in each study formulation are shown in table 2. Recommended daily allowance (RDA) values for nutrients included in the review are shown in table 3 (where RDA values have been determined).

Insert table 1.

Insert table 2.

Insert table 3.

\section{Statistical analysis}

One way of comparing the reliability of RCTs is to calculate the ability of the trial to detect a difference between treatment means. An approximate formula for this calculation is,

$\mathrm{R}=2 \mathrm{C} \sqrt{2} / \sqrt{ } \mathrm{r} \quad($ Ridgman, 1975) 
where ' $R$ ' is the percentage difference detectable in an experiment, ' $C$ ' is the coefficient of variation (the standard deviation as a percentage of the mean), and ' $r$ ' is the number of participants in each group. For example, if $R=10 \%$ then a true difference between the treatments of less than $10 \%$ is unlikely to be detected by the trial (Armstrong et al., 2000).

$R$ values have been calculated for the trials shown in table 4 because $C$ and $r$ could be determined. $\mathrm{R}$ values could not be calculated for the other trials reviewed because the required data was not available in the publications.

Insert table 4

\section{Review of trials}

\section{Zinc in AMD}

Subjects

A computer-generated table of random numbers was used to randomise 151 participants. For inclusion visual acuity in one eye had to be $20 / 80$ or better and ARM or AMD had to be evident by varying degrees of pigmentary change and drusen visualised with fundoscopy. 


\section{Experimental design}

The treatment group took one tablet containing $100 \mathrm{mg}$ of zinc sulphate twice daily and the placebo group took identical tablets containing lactose and fructose. All tablets were provided in identical containers.

\section{Outcomes}

Visual acuity with current glasses, pinhole visual acuity, colour vision, glare recovery time and serum zinc levels were all recorded, as well as fundus photographs. Masked independent observers graded baseline and final fundus photographs.

It has been found that zinc interacts with copper by stimulating metallothionein levels of the intestinal wall. Metallothionein binds to dietary copper preventing absorption, which leads to copper defiency. This can result in copper deficiency anaemia, since copper is required for production of erythrocytes (Dunlap et al., 1974; Fischer et al., 1983; Flanagan et al., 1983). Although copper was not included in the intervention formulation, the hematocrit (percentage of the whole blood that is comprised of red blood cells) was determined serially throughout the study period for each subject. No evidence of copper-deficiency anaemia was found.

\section{Results}

The investigators determined that the decrease in mean visual acuity in the zinc treated group was less than that of the placebo group (Newsome et al., 1988), 
in other words, zinc reduced progression of AMD (see figure 1). Figure 2 shows the change in the number of drusen assessed by each observer, for example, observer 1 found that 12 participants in the zinc group and 1 participant in the placebo group had fewer drusen at the end of the trial period than at baseline.

Figure 1 (Newsome et al., 1988).

Figure 2 (Newsome et al., 1988)

\section{Limitations}

Calculation of the $R$ value for this trial shows that it was unlikely to detect any difference between treatments smaller than $72 \%$ and that the results should be treated with caution. The authors suggest potential sources of bias including the use of subjects from a relatively small geographical area, and high soil and water mineral contents in this area.

Although five different parameters were measured, it would have been beneficial to measure the refractive error of subjects at each visit rather than relying upon pinhole visual acuities. The number of participants was small compared with the AREDS, ATBC and VECAT trials, but larger than the Visaline ${ }^{\circledR}$ trial. The use of a single nutrient provides more specific information about the role of zinc in AMD. 


\section{Visaline ${ }^{\circledR}$ in the treatment of AMD}

Subjects

This trial investigated the effect of Visaline ${ }^{\circledR}$ on the progression on AMD in 20 subjects with early stages of the condition. The subjects were over 50 years of age and had consulted an ophthalmologist due to non-exudative AMD. Follow up occurred at 3 and 6 months.

\section{Experimental design}

Visaline ${ }^{\circledR}$ is registered in Switzerland for the treatment of AMD. Eleven patients were allocated to Visaline ${ }^{\circledR}$ and nine to the placebo. Participants and investigators were masked as to intervention and placebo allocation. Two tablets were taken twice daily except for weekends, according to clinical recommendations.

\section{Outcomes}

Lens opacity was quantified with the Opacity Lens Meter (LOM) 701 (Interzeag, Switzerland), to assess the effect of cataract on results. This instrument assesses cataract by measuring the degree of scatter of a red light beam (700nm) by the lens (Clarke et al., 1990; Costagliola et al., 1990). Retinal visual acuity was measured using the Moire Interferometer (Haag-Streit, Berne, Switzerland). Macular function was evaluated using the Octopus field tester, and distance and near visual acuity, intra-ocular pressure, fundus inspection, contrast sensitivity and the Pandel-15 colour vision test were also measured. 
Results

Results showed no significant difference in measured parameters between the intervention and placebo groups.

\section{Limitations}

The fact that no treatment effect was determined is unsurprising considering the small sample size and the calculated $\mathrm{R}$ value for the study of $89 \%$. This means that the study was only likely to be capable of detecting a difference between treatments that was greater than $89 \%$. Interestingly, the effect of the Visaline ${ }^{\circledR}$ was subjectively considered to be more effective than placebo, despite the fact that the trial was designed to be double-masked. Investigators hypothesise that this could be a result of increased cerebral perfusion of buphenine (Kaiser et al., 1995), although no mechanism for this effect has been suggested. No information is given about the appearance, taste or smell of the placebo and intervention tablets, or about their packaging. It is possible that masking was not complete. As with AREDS and the ATBC study, the intervention formulation contained more than one substance, limiting the conclusions that may be drawn regarding specific nutrients.

Insert figure 3

An advantage of this trial is the fact that several visual parameters were measured. 


\section{Zinc and the second eye in AMD}

This study investigated the effect of zinc supplementation on progression to exudative $A M D$ in the second eye of patients with an exudative form of the disease in the first eye (Stur et al., 1996).

\section{Subjects}

One hundred and twelve subjects were enrolled, presenting with AMD and exudative lesions in one eye with a visual acuity better than 20/40, and AMD without any exudative lesion in the second eye.

\section{Experimental design}

Subjects were randomised into two groups, one receiving $200 \mathrm{mg}$ of zinc sulphate and the other receiving placebo, once daily. Tablets were coded and provided in identical containers, so that participants and investigators were masked. Intervention and placebo tablets were lemon flavoured and effervescent to improve gastrointestinal absorption.

\section{Outcomes}

Outcome measures were visual acuity, contrast sensitivity, colour discrimination and retinal grating acuity, as well as serum levels of zinc and copper, red blood cell count, and grading of fundus photography. This trial was the only one to include and grade fluoroscein angiography. Again, copper was not included in the intervention formulation but no significant change in red blood cell count 
was found during the treatment period, providing no evidence for onset of copper-deficiency anaemia.

Results

Investigators concluded that oral zinc substitution had no short-term effect on the course of AMD in patients with an exudative form of the disease in one eye.

\section{Limitations}

The investigators planned to recruit 500 participants, and had calculated the power of the trial to be $>80 \%$ based on this sample size. Recruitment was stopped in June 1993 after statistical evaluation by their sponsors failed to show any treatment benefit. The calculated $R$ value suggests that the trial was likely to be able to detect a treatment effect greater than $16 \%$, which is a much greater degree of precision than the Newsome et al. (1988) study.

\section{Alpha-tocopherol Beta-carotene Study (ATBC)}

Subjects

This trial was originally designed to investigate the role of $B C$ and vitamin $E$ (AT) in the prevention of lung cancer in over 29,000 smoking males. At the end of the trial an ophthalmological examination was carried out on a random sample of 941 male participants aged 65 years or over, to determine whether intervention with AT and/or BC had been associated with a difference in AMD prevalence (Teikari et al., 1998). The size of the main cancer trial provided a 
large base from which to select participants for the AMD branch, and the timescale increased the likelihood of determining change.

\section{Experimental design}

Participants were randomised into four groups, 1) AT only, 2) BC only, 3) AT and $\mathrm{BC}, 4)$ placebo. No information is provided about the appearance or packaging of the placebo and intervention tablets, but they are assumed to be identical as the original trial was designed to be double-masked and placebocontrolled.

\section{Outcomes}

This trial examined the inter-group differences in AMD prevalence. The level of AMD was assessed from fundus photography

Results

Investigators concluded that long-term supplementation of AT or BC does not affect the prevalence of ARM in smoking males (Teikari et al., 1998). Figure 4 shows the distribution of ARM and AMD by treatment group.

Insert figure 4

\section{Limitations}

A disadvantage of the study is that fundus photographs were not taken at baseline, which means that intra-group variation could not be assessed. The 
study was not likely to be powered to assess treatment effects for AMD as the number of participants graded with disciform degeneration or geographical atrophy was just 8/237 for AT, 3/257 for ATBC, 0/234 for BC, and 1/213 for placebo.

The study could have been improved by including measurement of clinical visual parameters such as central visual field analysis, colour vision, contrast sensitivity, and glare recovery. An equal spread of AMD at baseline is assumed due to randomisation, as well as the fact that mean visual acuity was similar in all four groups. Baseline visual acuity was also similar between those who chose to take part in the AMD section of the trial and those who did not, suggesting that selection bias is unlikely.

\section{Age-Related Eye Disease Study (AREDS)}

The AREDS trial had two main branches investigating the role of high dose nutrient supplementation on both $A M D$ and cataract. This review will mainly discuss the results of the AMD branch.

\section{Subjects}

Eleven retinal speciality clinics enrolled 3640 subjects from 1992 to 1998. Potential participants were identified from medical records of patients seen at AREDS clinics, referring physicians, patient lists from hospitals and health maintenance organisations, public advertisements, friends and family of study participants, screenings at shopping centres, health fairs, senior citizen centres 
and other gathering places. The range of ages was $55-80$ years with an average of 69 years. The following inclusion criteria were used; 20/32 in one eye, clear ocular media for fundus photography and one eye free from any disease that could complicate assessment of AMD. Participants were grouped into four main categories according to ARM or AMD stage, as shown in table 5.

Insert table 5 .

Participants in categories 2, 3 and 4 took part in both AMD and cataract branches and were randomised into four arms; 1) antioxidants, 2) zinc, 3) antioxidants plus zinc, 4) placebo. Category 1 patients (those showing no signs of $\mathrm{ARM}$ or $\mathrm{AMD}$ ) were only included in the cataract branch and so were randomised into antioxidant and placebo arms only. Zinc supplementation was not investigated in the cataract branch due to the lack of evidence for any beneficial effect of zinc supplementation on the progression of lens opacities, combined with the possible toxic effects of zinc.

\section{Experimental design}

The treatment and placebo tablets were allocated in coded bottles and participants and providers were masked. The placebo used in AREDS was identical in external appearance and similar in taste and internal appearance, to the active tablet. See table 2 for the formulation of the active tablets. 
Some nutritional supplement ingredients degrade throughout the life of the product and before the expiry date. Nutritional products are formulated with slightly different amounts of ingredients than listed in order to achieve appropriate potency at the expiry date. The AREDS tablets were formulated to give the following minimum amounts of each ingredient throughout the shelf life of the product:

Vitamin C (ascorbic acid)

$113 \mathrm{mg}$

Vitamin E (dl-alpha tocopheryl acetate)

$68 \mathrm{mg}$

(100IU)

Vitamin A (beta-carotene)

$4871 \mathrm{mg}$

(7160IU)

Zinc (zinc oxide)

$17.4 \mathrm{mg}$

Copper (cupric oxide)

$0.4 \mathrm{mg}$

Cupric oxide was added to the tablet formulation to offset the risk of copper deficiency anaemia. Vitamin C, vitamin E and zinc were included at much higher levels than RDA (see table 3). There is no RDA for beta-carotene. Two years into the AREDS the Alpha-Tocopherol, Beta-Carotene (ATBC) Cancer prevention Study group proved a relationship between beta-carotene and increased incidence of lung cancer in smoking males (The ATBC Cancer Prevention Study Group, 1994) . This was followed in 1996 by a report from the Beta-Carotene and Retinol Efficacy Trial (CARET) who noted that $28 \%$ more of the subjects taking beta-carotene developed lung cancer (Leo and Lieber, 1997). In 1996, smokers taking part in AREDS were given the option of discontinuing supplementation. Two percent (18\% of smokers in AREDS) discontinued supplementation in 1996. 


\section{Outcomes}

AMD was assessed using fundus photography and visual acuity was measured using logMAR EDTRS charts. Primary outcomes were progression to advanced AMD (AMD event) and a 15 letter or more decrease in visual acuity score (VA event). An AMD event was considered to be the development of neovascular AMD or development of geographical atrophy that involved the central macula.

Results

Table 6 shows the probability estimates of AMD events for each AMD category after five years.

Insert table 6.

In category 2, only 15 AMD events occurred after five years and these were evenly distributed across treatment arms. The investigators considered it impossible to assess treatment effects in this category with such a low event rate. Table 7 shows the probability of progression to advanced AMD by treatment arm for categories 3 and 4 .

Insert table 7. 
There was a $25 \%$ reduced risk of disease progression in those participants taking zinc plus antioxidants with intermediate or large drusen, non-central geographic atrophy, or advanced AMD in the second eye, as well as a 'suggestive' reduction in risk for the zinc arm (see figure 5).

Insert figure 5

Table 8 shows the probabilities of a visual acuity event (at least a 15 letter decrease in visual acuity score) between baseline and five years for categories 3 and 4.

Insert table 8.

Analysis of the results from categories 3 and 4 show a statistically significant reduced risk of a visual acuity event occurring in the antioxidant plus zinc arm compared to the placebo arm.

Definite serum responses to the study antioxidants were observed and are shown in tables 9 and 10.

Insert table 9.

Insert table 10. 
Participants taking zinc had an $18 \%$ increase in median serum level of zinc from baseline to year 1 . This was maintained throughout the 5-year period. Participants not assigned to a zinc group had smaller increases of $3 \%$ and $1 \%$. The median percent changes in serum levels of copper ranged from a $3 \%$ decrease to a $2 \%$ decrease across all treatment arms, indicating that copper levels were not affected by intervention of zinc oxide with cupric oxide.

These results suggest that the combination of zinc and antioxidants was 'modestly' effective in preventing progression to advanced AMD (The AREDS Research Group, 2001). This effect was seen only in those subjects with extensive intermediate drusen, large drusen or non-central geographic atrophy without advanced AMD. The effect was not seen with antioxidants alone, or in subjects with earlier or later stages of the condition. There was no statistically significant effect of delaying the progression of baseline category 2 eyes to categories 3 or 4 . The trial was likely to be adequately powered to assess this.

\section{Limitations}

In an attempt to standardise extra supplementation, the investigators asked participants who were already supplementing with zinc or antioxidants $(57 \%)$ to agree to take Centrum (Whitehall-Robins Healthcare, Madison, NJ) rather than any other nutritional supplements. Centrum was supplied to $95 \%$ of these participants, as well as an additional $13 \%$ who were not taking supplements when recruited. It would have been inappropriate to ask participants to stop taking other supplements as a pre-requisite to recruitment into the study. 
It has been argued that the reason an effect was found was because participants were also taking Centrum (Abramson and Abramson, 2002). Centrum, however, provides nutrients in concentrations of no more than $100 \%$ RDA (for nutrients where RDA values have been determined), and these levels could be obtained from the diet. As the intervention formulation introduced the study nutrients in much higher concentrations than RDA, the effect shown is more likely to be attributable to this and not variations in diet or extra supplementation.

Statistical analysis was restricted to a subgroup of categories 3 and 4 , which goes against standard clinical trial practice. AREDS investigators state that subgroup analysis was appropriate in this case as only 15 out of the expected 50 category 2 participants developed AMD (The AREDS Research Group, 2001). The statistical analysis method used by the AREDS Group does not allow the calculation of $R$, so that a measure of the degree of precision of this experiment cannot be determined. The AREDS investigators calculated that a sample size of 3600 would provide at least $80 \%$ power to detect a treatment effect of $25 \%$ to $50 \%$ on progression to advanced AMD. This sample size, however, included the category 2 participants.

The results of this trial may support the oxidative stress hypothesis for development of AMD. Unfortunately, it is not known whether this effect was initiated by one, or all of the nutrients, and to what degree. There was no 
statistically significant evidence to show that the intervention slowed the progression of ARM.

\section{Summary}

This trial forms an excellent platform for further research into the effect of nutritional supplementation on AMD. The outcome of this study highlights a need for the investigation of, short-term supplementation, individual nutrient supplementation, and the role of nutritional supplementation in preventing the onset of AMD. The AREDS investigators state that lutein and zeaxanthin were considered for inclusion in the formulation but that neither was readily available for manufacturing to a research formulation at AREDS initiation (The AREDS Research Group, 2001). The role of lutein and zeaxanthin in prevention of development and progression of AMD was highlighted for further research.

\section{Vitamin E, cataract, and age-related maculopathy trial (VECAT)}

The purpose of the AMD branch of this trial was to determine whether vitamin $E$ supplementation influences the incidence or rate of progression of AMD (Taylor et al., 2002).

\section{Subjects}

In total 1193 participants were randomised into two groups and followed up for four years. The investigators use the term 'early AMD' as opposed to ARM and the grading system used is shown in table 11. 
Insert table 11.

\section{Experimental design}

The intervention group took 500IU (approximately 335mg) of $d-\alpha$ tocopherol daily for four years. The placebo was identical in sight, taste and smell.

\section{Outcomes}

The primary outcome was development of 'early AMD 3' and secondary outcomes were the progression of $A M D$ and development of late $A M D$, changes in visual acuity and changes in visual function. Visual function was measured using the Visual Function Index (VF-14) (Linder et al., 1999). The incidence of early AMD was defined as the appearance of early AMD in at least one eye of participants who did not have early AMD in either eye at baseline. Stereophotographs of the macula were graded independently.

\section{Results}

No significant difference was found in incidence or progression of early AMD between intervention and placebo groups. The trial concluded that daily supplementation with vitamin $\mathrm{E}$ does not prevent development or progression of early AMD (Taylor et al., 2002). 


\section{Limitations}

No measurement of the degree of precision of the trial is available as the data provided does not permit calculation of $R$. The trial is unlikely to be adequately powered for assessment of treatment effect in the 'early AMD 4' and 'late AMD' categories as photographs graded for these groups constituted only $2 \%$ (vitamin E) and $3 \%$ (placebo) of the participants at 4 years. Having said this, photographs appear to have been graded for a total of $56 \%$ of the vitamin $E$ group and $61 \%$ of the placebo group at baseline, and $55 \%$ and $54 \%$ respectively at four years. This could indicate that the remaining photographs were not of high enough quality for grading purposes, and the $7 \%$ reduction in the number of photographs graded between baseline and four weeks in the placebo group may suggest a high drop-out rate.

The trial was designed with the measurement of various outcome parameters and the masking of treatment and placebo groups. Measurement of parameters such as glare recovery, contrast sensitivity and colour vision would have enhanced the trial. The intervention however, contained a single nutrient, which provides a more conclusive answer to the role of vitamin E in AMD.

\section{The Lutein Antioxidant Supplementation Trial (LAST)}

The results of this RCT investigating the role of lutein on progression of atrophic AMD have been published in abstract form. 
Subjects

Ninety, mostly male veterans $(74.7+/-7.1$ years $)$ with atrophic AMD were recruited.

\section{Experimental design}

Participants were randomised into three treatment groups; 1) 10mg lutein, 2) 10mg lutein/antioxidants, 3) placebo, and were matched for age, years diagnosed with AMD, smoking/cardiovascular history, iris colour, lens opacification and nutritional status/activity level.

\section{Outcomes}

Outcome measures were macular pigment optical density (MPOD) measurement, lens opacification rating, glare recovery, low-luminance lowcontrast visual acuity, contrast sensitivity, and activities of daily living associated with AMD (night driving/glare adaptation disturbance).

\section{Results}

Investigators have reported a statistically significant concurrent improvement in glare recovery, contrast sensitivity, and distance/near visual acuity in both treatment groups. Combining lutein with other antioxidants appears to provide added improvement to contrast sensitivity (Richer et al., 2002). 
See table 12 for a summary of the outcomes of the RCTs discussed in this review.

Insert table 12.

\section{Discussion}

\section{Vitamin C in AMD}

Vitamin C is a water-soluble antioxidant and acorbic acid has been shown to react directly with hydroxyl radicals (Bielski, 1982), superoxide (Nishikimi, 1975; Hemila et al., 1985), and singlet oxygen (Bodannes and Chan, 1979). The EDCCS reported that low plasma levels of vitamin C were associated with increased risk of AMD, but high levels were not found to be protective (EDCCS Group, 1993). Its role in protecting against free radical-mediated oxidative tissue damage may have wide implications in retarding disease progression (Department of Health, 1992).

\section{Vitamin E in AMD}

Vitamin $E$ exists in four common forms; $\alpha$-tocopherol, $\beta$-tocopherol, $Y$ tocopherol, and $\delta$-tocopherol (Drevon, 1991). The most predominant form in the human retina and plasma is a-tocopherol (Handelman et al., 1985; Alvarez et al., 1987), which is also the most effective scavenger of free radicals (Burton. and Ingold, 1984). Evidence that it may protect against AMD comes from 
observational evidence of dietary and blood levels of vitamins and nutrients in AMD patients (Teikari et al., 1998). It is found in high concentrations within the retina (Dilley, 1970; Hunt, 1984), and as the major lipid-soluble antioxidant present in all cellular membranes, protects against lipid peroxidation (Machlin, 1980). Vitamin E may also have a role as a quencher of singlet oxygen and plasma concentration reduces with age. Higher dietary intake of vitamin $\mathrm{E}$ can increase its concentration in the retina (Seddon, 1999), and a relationship has been found between greater plasma vitamin $E$ levels and a reduced risk of AMD (Delcourt et al., 1999).

\section{Zinc in AMD}

Zinc is highly concentrated in ocular tissues, particularly the retina and pigment epithelium (Siegel et al., 1961; Galin et al., 1962; Swanson and Truesdale, 1971; Eckhert, 1979; Ujiie, 1979). It acts as a cofactor for the antioxidant enzymes retinal dehydrogenase and catalase (Sigel, 1983) and is also involved in retinal metabolism. The elderly are at risk from zinc deficiency (Solomons, 1979; Turnland et al., 1981; Wagner et al., 1983; Wagner, 1985), which can lead to a reduction in $\mathrm{T}$ lymphocytes and $\mathrm{B}$ lymphocytes through increased apoptosis. Zinc deficiency also compromises the function of another immunological cell, the macrophage (Berger, 2002).

Zinc is the second most abundant trace mineral in the body (Karcioglu, 1982) and plays a part in numerous enzyme systems within the eye, including alkaline phosphatase, carbonic anhydrase (important in aqueous production) and 
enzyme systems concerned with metabolism and nucleic acids (Karcioglu, 1982). Zinc is a cofactor for retinal dehydrogenase, which is involved in metabolism of a vitamin A transport protein, and also the interconversion of retinol to retinal, which is essential for rhodopsin synthesis (Solomons and Russell, 1980). Zinc deficiency can alter the function of alcohol dehydrogenase in the retina (Huber and Gershoff, 1975), which can result in increased overall vitamin A uptake. The possible accumulation of retinyl esters in the RPE may interfere with normal biosynthesis and could also produce a toxic effect. In the same way, zinc deficiency promotes lipid peroxidation and damage to lipid membranes (McClain et al., 1985).

\section{Beta-carotene in AMD}

Carotenoids are regarded as effective antioxidants and beta-carotene has a well documented role as a quencher of singlet oxygen radicals (Burton and Ingold, 1984a). They are pigments which exist in marigolds, coloured fruit and dark green, leafy vegetables (Khachik and Beecher, 1987; Khachik and Beecher, 1988; Khachik et al., 1989; Ong and Tee, 1992; Mangels et al., 1993; Sommerburg et al., 1998). Beta-carotene is the major carotenoid precursor of vitamin A. Vitamin A cannot quench singlet oxygen and has only a very small capacity to scavenge free radicals (Urbach et al., 1951; Mathews-Roth, 1986).

\section{Protective role of carotenoids in AMD}

Over recent years the amount of evidence supporting the protective role of carotenoids in the retina has increased. Lutein, zeaxanthin, and meso- 
zeaxanthin, which are oxygenated carotenoids known as xanthophylls, form the macular pigment (MP) (Bone et al., 1985; Khachik et al., 1997). It has been shown that the xanthophylls have superior antioxidant properties to hydrocarbon carotenoids such as beta-carotene and exhibit a smaller tendency towards pro-oxidant behaviour (Martin et al., 1999). These nutrients are obtained by the human body exclusively from dietary sources (Khachik et al., 1991; Khachik et al., 1992) and are, for example, found in marigold flowers, mango, papya, kiwi, peaches, spinach, squash, and honeydew melon. The normal Western diet contains $1.3-3 \mathrm{mg}$ per day of lutein and zeaxanthin combined (Landrum and Bone, 2001); the recommended daily intake of lutein is $6 \mathrm{mg}$ (Seddon, 1999). This value was determined by the EDCCS group, where investigators found that participants with a daily lutein intake above the highest quintile (6mg) had a decreased risk of neovascular AMD (EDCCS Group, 1992).

Lutein and zeaxanthin reach their greatest concentrations at the centre of the fovea and diminish with eccentricity (Snodderly et al., 1991; Hammond et al., 1997; Beatty et al., 1999; Landrum and Bone, 2001). They are present in the axons of the photoreceptors and are responsible for the 'yellow spot' at the macula (Snodderly et al., 1984). In vivo the 'yellow spot' appears dark when viewed under blue light due to the absorption of the blue wavelengths by the yellow pigment (Schalch, 2001). Wald first demonstrated that this macular pigment exhibited a characteristic xanthophyll absorption spectrum (Wald, 
1945), and later, the presence of lutein and zeaxanthin in the macula was established (Handelman et al., 1988).

The MPOD can vary within an individual depending on diet and lifestyle (Beatty et al., 2000). Psychophysical techniques used to measure the quantity of MP in the living eye include colour matching, motion anomaloscope, spectral sensitivity and heterochromic flicker photometry (HCFP) (Mellerio, 2001; Bernstein, 2002). Until recently HCFP has been the most commonly used technique, the basic is theory based on the difference between foveal and parafoveal sensitivities to blue light being used as a measure of optical pigment density (Mellerio, 2001). Most recently, a technique based on resonance Raman spectroscopy has been used. Most compounds scatter monochromatic light at the same wavelength, a phenomenon called Rayleigh scattering. A small proportion of the monochromatic light is scattered at different wavelengths that are determined by the molecular structure of the compound, a phenomenon known as Raman scattering. All carotenoids measured in vivo or in vitro have very similar Raman spectra because they share a similar chemical structure. This technique is valuable as an objective measure of macular pigment levels, as opposed to the subjective flicker photometry. Studies using this technique have determined that macular pigment levels decline with age and that levels are significantly lower in non-supplemented AMD eyes compared with agematched controls (Bernstein, 2002). 
Low MPOD, measured using a flicker photometry-based technique, has been found in obese subjects compared with those of normal weight. The MPOD of subjects with body mass index (BMI) greater than 29 was 21\% less than subjects with a lower BMI (Hammond et al., 2002). This could be explained by the fact that up to $80 \%$ of the total carotenoids in the body are found in adipose tissue (Olson, 1984). Another study using scanning laser ophthalmoscopy and reflectometry techniques found that a daily dose of $6 \mathrm{mg}$ of lutein induced an increase in mean plasma lutein by a factor of 5 and a linear 4-week increase in relative macular pigment (MP) density of $4 \%$ to $5 \%$ (Berendschot et al., 2000).

An age-related decline in the MPOD was found in a group from a Northern European population using heterochromic flicker photometry. This study also found significantly less MP in eyes judged to be at high risk for AMD compared with age-matched controls (Beatty et al., 2001). A previous study had also found a statistically significant inverse relationship between the MPOD and age among subjects living in Arizona (Hammond and Caruso-Avery, 2000). These results contrast with the results of earlier studies on the effects of aging on MPOD (Werner et al., 1987; Bone et al., 1988), although these trials did not take into account more recently identified risk factors such as gender (EDCCS Group, 1992; Klein et al., 1992; Vinding, 1995), and smoking (Klein et al., 1993; Seddon et al., 1996; Smith and Mitchell, 1996; Vingerling et al., 1996; Tamakoshi et al., 1997; Hawkins et al., 1999). A further case-control study found an inverse association between risk of AMD and MPOD, although the authors state that this does not imply a causal association (Bone et al., 2001). 
Protective mechanisms of lutein and zeaxanthin

Lutein and zeaxanthin are believed to protect the retina in two ways. Firstly, they filter short wavelengths of light and so reduce the oxidative effect of blue light (Ham, 1983; Ham et al., 1984). These carotenoids act effectively as a bluelight filter for a number of reasons. Action spectrum for light-induced damage shows a maximum at $400 \mathrm{~nm}$ and $450 \mathrm{~nm}$ which is consistent with the absorption spectrum of macular pigment (Ham et al., 1984) This is known as the 'blue light hazard function' (Ham and Mueller, 1989). As previously mentioned, the macular pigment reaches its highest concentration in the foveal region, and it has been shown that the orientation of the pigment molecules enhances light absorption (Farber et al., 1985; Beatty et al., 1999). The distribution of macular pigment through photoreceptor cells means that each cell screens other cells as well as itself due to the lateral course of the axons (Farber et al., 1985).

Secondly, carotenoids limit oxidant stress of tissue resulting from metabolism and light (Ham, 1983; Schalch, 1992; Khachik et al., 1997). There are two known mechanisms by which carotenoids quench free radicals. Energy transfer to the carotenoid quenches singlet oxygen. The carotenoid is then able to relax without destructive bond-breaking. The ability to quench free radicals depends on the conjugate double bonds within their molecular structure. Carotenoids are also believed to react with peroxy radicals which are involved with lipid peroxidation (Landrum and Bone, 2001). 


\section{Conclusion}

It is difficult to compare the results of the studies described here as there are many variables. The results of zinc supplementation determined by Newsome et al. (1988), were not confirmed by Stur et al. (1996). This is important in that the participants of this second trial were at higher risk of AMD because they already had an exudative form of the condition in one eye. It is interesting to note that a positive effect of zinc supplementation was determined from the Newsome et al. (1988) trial, despite the lower calculated degree of precision. Widespread use of zinc supplementation was not recommended due to the risk of copper deficiency anaemia (Dunlap et al., 1974; Fischer et al., 1983; Flanagan et al., 1983) as well as a potential side effect of worsening of cardiovascular disease. People with ischaemic heart disease have been shown to have reduced levels of cardiac and leucocyte copper, as well as decreased activity of some copper-dependant enzymes (Klevay, 2000).

The AREDS formed a much larger zinc intervention trial, and found a 'suggestive' reduction in the risk of progression to advanced AMD in category 3 and 4 participants (see table 6). These results may suggest a beneficial role of zinc in this subsection of AMD patients, particularly those who smoke and are therefore contraindicated from beta-carotene.

The Newsome and Stur studies used 200mg zinc sulphate; the AREDS used $80 \mathrm{mg}$ zinc oxide. Although zinc oxide has the relatively poorer bioavailibility of the two, the most bioavailable forms of zinc are zinc citrate, gluconate, monomethionine, and picolinate (Lazarides, 1997). Using a more bioavailable 
form of zinc may have produced a greater treatment effect, but is likely to have also induced more toxicity issues.

Although the amounts of vitamin E used in the VECAT and AREDS differ, (335mg and $273 \mathrm{mg}$ respectively), these amounts are both much higher than RDA (15mg). The different conclusions made by these trials could suggest that supplementation with vitamin $E$ is only effective in combination with other nutrients. The negative result from the ATBC trial accommodates this theory, although a lower dose of $50 \mathrm{mg}$ was used and it was combined with $20 \mathrm{mg}$ of beta-carotene. This trial differs from the others in that only male smokers were enrolled. There was no evidence for a role of nutritional supplementation in slowing the progression of ARM in any of these three studies. The data from the AREDS category 2 participants is positive for patients with extensive small drusen, pigment abnormalities, or at least one intermediate sized druse, as it indicates a $1.3 \%$ probability of progression to advanced AMD after 5 years. The antioxidant arm of the AREDS trial contains the same nutrients as the Visaline ${ }^{\circledR}$ trial with the exception of buphenine. However, the doses are vastly different making comparison impossible.

There is evidence to support the hypotheses that antioxidants such as vitamin $\mathrm{C}, \mathrm{E}$, carotenoids and zinc may play a role in reducing the risk of progression of AMD (The AREDS Research Group, 2001; Richer et al., 2002). Lutein and zeaxanthin were considered for inclusion in the AREDS formulation, and it is known that they are oxygenated carotenoids, which make up the MP. Their role 
in the treatment of AMD has been investigated in the LAST, where results indicated reversal of AMD symptoms. These findings may represent a breakthrough in the therapeutic approach to AMD management, and warrant further investigation.

\section{Acknowledgements}

Hannah Bartlett is funded by the College of Optometrists. The authors would like to thank Dr Richard Armstrong for advice on statistical analysis. 


\section{References}

Abramson, D. and Abramson, H. (2002). High-Dose Supplements for AgeRelated Macular Degneration: Did You Leave Out Centrum? Archives of Ophthalmology. 120, 1602.

Algvere, P. V. and Seregard, S. (2002). Age-related maculopathy: pathogenetic features and new treatment modalities. Acta Ophthalmol. Scand. 80, 136-143.

Alvarez, R., Liou, G. and Fong, S. (1987). Levels of alpha- and gammatocopherol in human eyes: evaluation of the possible role of IRBP in intraocular alpha-tocopherol transport. Am J Clin Nutr. 46, 481-487.

Armstrong, R., Slade, S. and Eperjesi, F. (2000). An introduction to analysis variance (ANOVA) with special reference to data from clinical experiments in optometry. Ophthal. Physiol. Opt. 20, 235-241.

Beardsley, T. (1991). The A Team. Vitamin A and its cousins are potent regulators of cells. Sci. Am. 16-19.

Beatty, S., Boulton, M., Henson, D., Koh, H. H. and Murray, I. J. (1999). Macular pigment and age related macular degeneration. Br. J. Ophthalmol. 83, 867-877.

Beatty, S., Koh, H., Carden, D. and Murray, I. (2000). Macular pigment optical density measurement: a novel compact instrument. Ophthal. Physiol. Opt. 20, 105-111.

Beatty, S., Murray, I. J., Henson, D. B., Carden, D., Koh, H. and Boulton, M. E. (2001). Macular pigment and risk for age-related macular degeneration in subjects from a Northern European population. Invest. Ophthalmol. Vis. Sci. 42, 439-446.

Berendschot, T. T., Goldbohm, R. A., Klopping, W. A., van de Kraats, J., van Norel, J. and van Norren, D. (2000). Influence of lutein supplementation on macular pigment, assessed with two objective techniques. Investigative Ophthalmology \& Visual Science. 41, 3322-3326.

Berger, A. (2002). Science commentary: What does zinc do? Br. Med. J. 325, 1063-1063.

Bernstein, P. S. (2002). New insights into the role of the macular carotenoids in age- related macular degeneration. Resonance Raman studies. Pure Appl. Chem. 74, 1419-1425.

Bielski, B. (1982). Chemistry of ascorbic acid radicals. Ascorbic acid: chemistry, metabolism, and uses. Adv Chem Ser. 200, 81-100. 
Bird, A. (1996). Age-related macular disease. Br. J. Ophthalmol. 80, 2-3.

Bird, A. and Marshall, J. (1986). Retinal pigment epithelium detachments in the elderly. Trans Ophthalmol Soc UK. 105, 674-682.

Bird, A. E. C., Bressler, N. M., Bressler, S. B., Chisholm, I. H., Coscas, G., Davis, M. D., Dejong, P., Klaver, C. C. W., Klein, B. E. K., Klein, R., Mitchell, P., Sarks, J. P., Sarks, S. H., Sourbane, G., Taylor, H. R. and Vingerling, J. R. (1995). An International Classification and Grading System for Age- Related Maculopathy and Age-Related Macular Degeneration. Surv. Ophthalmol. 39, 367-374.

Bischoff, P. and Flower, R. (1983). High blood pressure in choroidal arteries as a possible pathogenetic machanism in senile macular degeneration. $A m$. J. Ophthalmol. 96, 398-399.

Bodannes, R. and Chan, P. (1979). Ascorbic acid as a scavenger of singlet oxygen. FEBBS Lett. 105, 195-196.

Bone, R., Landrum, J. and Tarsis, S. (1985). Preliminary identification of the human macular pigment. Vision Res. 25, 1531-1535.

Bone, R., Landrum, J. T. and Fernandez, L. (1988). Analysis of the macular pigment by HPLC: retinal distribution and age study. Invest. Ophthalmol. Vis. Sci. 29, 843-849.

Bone, R. A., Landrum, J. T., Mayne, S., Gomez, C., Tibor, S. and Twaroska, E. (2001). Macular pigment in donor eyes with and without AMD: A casecontrol study. Invest Ophthalmol Vis Sci. 42, 235-240.

Bressler, N. M. and Bressler, S. B. (1995). Preventative Ophthalmology - AgeRelated Macular Degeneration. Ophthalmology. 102, 1206-1211.

Burton, G., Foster, D., Perly, B., Slater, T., Smith, I. and Ingold, K. (1985). Biological antioxidants. Philos. Trans. R. Soc. Lond. B Biol. Sci. 311, 565-578.

Burton, G. and Ingold, K. (1984a). Beta-carotene: an unusual type of lipid antioxidant. Science. 224, 569-573.

Burton., G. and Ingold, K. (1984). Autoxidation of biological molecules: 1: The antioxidant activity of vitamin $E$ and related chain-breaking phenolic antioxidants in vitro. J Am Chem Assoc. 103, 6472-6477.

Chuang, E. and Bird, A. (1988). The pathogenesis of tears of the retinal pigment epithelium. Am. J. Ophthalmol. 105, 185-190. 
Clarke, M. P., Pearson, J. C. G., Vernon, S. A. and Matthews, J. C. (1990). Influence of Pupil Size on Measurements Made with the Lens Opacity Meter 701. Br. J. Ophthalmol. 74, 526-527.

Costagliola, C., Iuliano, G., Marino, E., Paolercio, F., Trapanese, A. and Apponibattini, G. (1990). Quantification and Measurement of Human Lens Opacities Using the Lens Opacity Meter. Ophthalmologica. 201, 4548.

Curcio, C. and Millican, C. (1999). Basal linear deposits and large drusen are specific for early age-related maculopathy. Arch. Ophthalmol. 117, 329339.

Delcourt, C., Cristol, J. P., Tessier, F., Leger, C. L., Descomps, B. and Papoz, L. (1999). Age-related macular degeneration and antioxidant status in the POLA study. Arch. Ophthalmol. 117, 1384-1390.

Department of Health 1992 The Nutrition of Elderly People Report on Health and Social Subjects. HMSO, London,

Dilley, R., A; McConnell,D,G. (1970). Alpha-tocopherol in the retinal outer segment of bovine eyes. J. Membr. Biol. 2, 317-323.

Drevon, C. (1991). Absorption, transport and metabolism of vitamin E. Free Radic Res Commun. 14, 229-246.

Dunlap, W., James, G. and Hume, D. (1974). Anaemia and neutropenia caused by copper deficiency. Annals of Internal Medicine. 80, 470-476.

Eckhert, C. (1979). A comparative study of the concentrations of $\mathrm{Ca}, \mathrm{Fe}, \mathrm{Zn}$ and Mn in ocular tissues. Fed Proc. 38, 872.

EDCCS Group (1993). Antioxidant status and neovascular age-related macular degeneration. The Eye Disease Case Control Study Group. Arch. Ophthalmol. 111, 104-109.

EDCCS Group (1992). Risk Factors for age-related macular degeneration. The Eye Disease Case-Control Study Group. Arch. Ophthalmol. 110, 1701-8.

Evans, J. (2002). Antioxidant vitamin and mineral supplementation for preventing age-related macular degeneration. The Cochrane Library.

Evans, J. and Wormald, R. (1996). Is the incidence of registrable age-related macular degeneration increasing? Br. J. Ophthalmol. 80, 9-14.

Farber, D., Flannery, J., Lolley, R. and Bok, D. (1985). Distribution patterns of photoreceptors, protein, and cyclic nucleotides in the human retina. Invest. Ophthalmol. Vis. Sci. 26, 1558-68. 
Feeney-Burns, L. and Ellersieck, M. (1985). Age-related changes in the ultrastructure of Bruch's membrane. Am. J. Ophthalmol. 100, 686-697.

Fischer, P., Giroux, A. and L'Abbe, M. (1983). Effects of zinc on mucosal copper binding and on the kinetics of copper absorption. J. Nutr. 113, 462-469.

Flanagan, P., Haist, J. and Valberg, L. (1983). Zinc absorption, intraluminal zinc and intestinal metallothionein levels in zinc-deficient and zinc-replete rodents. J. Nutr. 113, 962-972.

Friedman, E., Krupsky, S., Lane, A., Oak, S., Friedman, E., Egan, K. and Gragoudas, E. (1995). Ocular blood flow velocity in age-related macular degeneration. Ophthalmology. 102, 640-646.

Fukuzawa, K. and Gebicki, J. (1983). Oxidation of alpha-tocopherol in micelles and liposomes by the hydroxyl, perhydroxyl, and superoxide free radicals. Arch. Biochem. Biophys. 226, 242-251.

Galin, M., Nano, H. and Hall, T. (1962). Ocular zinc concentration. Invest Ophthalmol Vis Sci. 1, 142-148.

Gey, K., Stahalin, H. and Eichholzer, M. (1993). Poor plasma status of carotene and vitamin $\mathrm{C}$ is associated with higher mortality from ischaemic heart disease and stroke: Basel Prospective Study. Clin. Investig. 71(1), 3-6.

Gray, J. A. M. (1997). Evidence-based healthcare. How to make health body and mangement decisions. Churchill Livingstone,

Halliwell, B. G. J., M,C. (1999). Free Radicals in Biology and Medicine. Oxford University Press. 3rd edition,

Ham, W. (1983). Ocular hazards of light sources: review of current knowledge. J Occup Med. 25, 101-103.

Ham, W., Mueller, H. and Ruffolo, J. (1984). Basic mechanisms underlying the production of photochemical lesions in the mammalian retina. Curr Eye Res. 3, 165-174.

Ham, W. and Mueller, W. 1989 The photopathology and nature of the blue-light and near-UV retinal lesion produced by lasers and other optical sources Laser Applications in Medicine and Biology Plenum Press, New York, 191-246.

Hammond, B. and Caruso-Avery, M. (2000). Macular pigment optical density in a Southwestern sample. Invest Ophthalmol Vis Sci. 41, 1492-1497. 
Hammond, B. J., Wooten, B. and Snodderly, D. (1997). Individual variations in the spatial profile of human macular pigment. J Am Optom Assoc. 14, 1187-1196.

Hammond, B. R., Ciulla, T. A. and Snodderly, D. M. (2002). Macular pigment density is reduced in obese subjects. Invest. Ophthalmol. Vis. Sci. 43, 47-50.

Handelman, G., Dratz, E. and Reay, C. (1988). Carotenoids in the human macula and the whole retina. Invest Ophthalmol Vis Sci. 29, 850-855.

Handelman, G., Machlin, L. and Fitch, K. (1985). Oral alpha-tocopherol supplements decrease plasma gamma-tocopherol levels in humans. $J$ Nutr. 115, 807-813.

Hawkins, B. S., Bird, A., Klein, R. and West, S. K. (1999). Epidemiology of agerelated macular degeneration. Mol. Vis. 5, U7-U10.

Hemila, H., Roberts, P. and Wikstrom, M. (1985). Activated polymorphonuclear leucocytes consume vitamin C. FEBS Letters. 178, 25-30.

Huber, A. and Gershoff, S. (1975). Effects of zinc deficiency on the oxidation of etinol and ethanol in rats. Nutrition. 105, 1486-1490.

Hulley, S., Cummings, S., Browner, W., Grady, D., Hearst, N. and Newman, T. (2001). Designing Clinical Research. Lippincott Williams \& Wilkins, Philadelphia.

Hunt, D., F; Organisciak,D,T; Wu,R,C (1984). Alpha-tocopherol in the developing rat retina: a high pressure liquid chromatographic analysis. Curr. Eye Res. 3, 1281-1288.

Huwiler-Muntener, K., Juni,P., Junker,C., Egger,M. (2002). Quality of Reporting Randomized Trials as a Measure of Methodologic Quality. J. Am. Med. Soc. 287, 2801-2804.

Hyman, L. G., Lilienfeld, A. M., Ferris, F. L. and Fine, S. L. (1983). Senile Macular Degeneration - a Case-Control Study. Am. J. Epidemiol. 118, 213-227.

Ishibashi, T., Sorgente, N., Patterson, R. and Ryan, S. (1986). Pathogenesis of drusen in the primate. Invest Ophthalmol Vis Sci. 27, 184-193.

Jacques, P. (1992a). Relationship of vitamin C status to cholesterol and blood pressure. Ann. N. Y. Acad. Sci. 669, 205-214.

Jacques, P. F. (1992b). Effects of vitamin C on high density lipoprotein cholesterol and blood pressure. Am J Coll Nutr. 11(2), 139-144. 
Kaiser, H. J., Flammer, J., Stumpfig, D. and Hendrickson, P. (1995). Visaline(R) in the Treatment of Age-Related Macular Degeneration - a Pilot-Study. Ophthalmologica. 209, 302-305.

Kaplan, J., BGerber, S. and Larget-Piet, D. (1993). A gene for Stargardt's disease(fundus flavimaculatus) maps to the short arm of chromosome 1. Nat. Genet. 5, 308-311.

Karcioglu, Z. (1982). Zinc and the eye. Surv. Ophthalmol. 27, 114-122.

Khachik, F. and Beecher, G. (1987). Application of a c-45-b-carotene as an internal standard for the quantification of carotenoids in yellow/orange vegetables by liquid chromatography. J. Agric. Food Chem. 35, 732-738.

Khachik, F. and Beecher, G. (1988). Separation and identification of carotenoids and carotenol fatty acid esters in some squash products by liquid chromatography. 1. Quantification of carotenoids and related esters by HPLC. J. Agric. Food Chem. 36, 929-937.

Khachik, F., Beecher, G. and Goli, M. 1992 Separation and quantification of carotenoids in foods Methods Enzymol. Academic Press, San Diego, 347-359.

Khachik, F., Beecher, G. and Goli, M. (1991). Separation, identification, and quantification of carotenoids in fruits, vegetables and human plasma by higg performance liquid chromatography. Pure Appl. Chem. 63, 71-80.

Khachik, F., Beecher, G. and Lusby, W. (1989). Separation, identification, and quantification of the major carotenoids in extracts of apricots, peaches, cantaloupe and pink grapefruit by liquid chromoatography. J. Agric. Food Chem. 37, 1465-1473.

Khachik, F., Bernstein, P. S. and Garland, D. L. (1997). Identification of lutein and zeaxanthin oxidation products in human and monkey retinas. Invest Ophthalmol Vis Sci. 38, 1802-1811.

Klein, R., Klein, B. and Franke, T. (1993). The relationship of cardiovascular disease and its risk factors to age-related maculopathy: the Beaver Dam Eye Study. Ophthalmology. 100, 406-414.

Klein, R., Klein, B. E. K. and Linton, K. L. P. (1992). Prevalence of Age-Related Maculopathy - the Beaver Dam Eye Study. Ophthalmology. 99, 933-943.

Klein, R., Wang, Q. and Klein, B. (1995). The relationship of age-related maculopathy, cataract, and glaucoma to visual acuity. Invest Ophthalmol Vis Sci. 36, 182-191. 
Klevay, L. M. (2000). Cardiovascular disease from copper deficiency - a history. J. Nutr. 130 (2), 489S-492S.

Kornzweig, A. (1977). Changes in the choriocapillaris associated with senile macular degeneration. Ann Ophthalmol. 9, 753-764.

Landrum, J. T. and Bone, R. A. (2001). Lutein, zeaxanthin, and the macular pigment. Arch. Biochem. Biophys. 385, 28-40.

Lazarides, L. (1997). The Nutritional Health Bible. Harper Collins, London.

Leo, M. A. and Lieber, C. S. (1997). Risk factors for lung cancer and for intervention effects in CARET, the Beta-Carotene and Retinol Efficacy Trial. J. Natl. Cancer Inst. 89, 1722-1723.

Linder, M., Chang, T. S., Scott, I. U., Hay, D., Chambers, K., Sibley, L. M. and Weis, E. (1999). Validity of the Visual Function Index (VF-14) in patients with retinal disease. Arch. Ophthalmol. 117, 1611-1616.

Machlin, L. (1980). Vitamin E: a comprehensive treatise. Dekker, New York.

Machlin, L. and Bendich, A. (1987). Free radical tissue damage:protective role of antioxidant nutrients. Faseb J. 1, 441-445.

Mangels, A., Holden, J. and Beecher, G. (1993). Carotenoid content of fruits and vegetables: an evaluation of analytic data. J. Am. Diet. Assoc. 93, 284-296.

Manson, J., Stampfer, M. and Willett, W. (1991). A prospective study of antioxidant vitamins and incidence of coronary heart disease in women. Circulation. 84(II), 546 (abstract).

Martin, H., Ruck, C., Schmidt, M., Sell, S., Beutner, S., Mayer, B. and Walsh, R. (1999). Chemistry of carotenoid oxidation and free radical reactions. Pure and Applied Chemistry. 71, 2253-2262.

Mathews-Roth, M. (1986). Beta-carotene therapy for erythropoietic protoporphyria and other photosensitivity diseases. Biochemie. 68, 875884.

McCay, P. (1985). Vitamin E: interactions with free radicals and ascorbate. Ann. Rev. Nutr. 5, 323-340.

McClain, C., Kararskis, E. and Allen, J. (1985). Functional consequences of zinc deficiency. Prog Food Nutr Sci. 9, 185-226.

Mellerio, J. (2001). Characteristics of Macular Pigment May Be Used to Measure Pigment Density Psychophysically. Report of the Special 
Interest Symposium: Xanthophyll Carotenoids and the Macular Pigment Lutein.

Moore, D., Hussain, A. and Marshall, J. (1995). Age-related variation in the hydraulic conducitivity of bruch's membrane. Invest Ophthalmol Vis Sci. 36, 1290-1297.

Newsome, D. A., Swartz, M., Leone, N. C., Elston, R. C. and Miller, E. (1988). Oral Zinc in Macular Degeneration. Arch. Ophthalmol. 106, 192-198.

Nishikimi, M. (1975). Oxidation of ascorbic acid with superoxide anion generated by the xanthine-xanthine oxidase system. Biochem. Biophys. Res. Commun. 63, 463-468.

Olson, J. A. (1984). Serum levels of vitamin A and carotenoids as reflectors of nutritional status. J Natl Cancer Inst. 73, 1439-1444.

Ong, A. and Tee, E. 1992 Natural sources of carotenoids from plants and oils Methods Enzymol. Academic Press, London, 142-167.

Osilesi, O., Trout, D. and Ogunwole, J. (1991). Blood pressure and plasma lipids during ascorbic acid supplementation in borderline hypertensive and normotensive adults. Nutr. Res. 11, 402-412.

Ozawa, T., Hanaki, A. and Matsuo, M. (1983). Reactions of superoxide ion with tocopherol and model compounds: correleation between the physiological activities of tocopherols and the concentration of chromanoxyl-radicals. Biochem. Int. 6, 685-692.

Pauleikhoff, D., Harper, C., Marshall, J. and Bird, A. (1990). Ageing changes in Bruch's membrane. A histochemical and morphological study. Ophthalmology. 97, 171-178.

Pippenger, C., Zianzhong, M. and Rothner, D. 1991 Free radical scavenging enzyme activity profiles in risk assessment of idiosyncratic drug reactions Idiosyncratic reactions to valproate: clinical risk patterns and mechanisms of toxicity Raven Press, New York, 75-88.

Potts, A. (1966). An hypothesis on macular disease. Trans Am Acad Ophthalmol Otolaryngol. 70, 1058-1062.

Richer, S., Stiles, W., Statkute, L., Pei, K., Frankowski, J., Nyland, J., Pulido, J. and Rudy, D. (2002). The Lutein Antioxidant Suplementation Trial (EAbstract 2542). Invest Ophthalmol Vis Sci. 43,

Ridgman, W. (1975). Experimentation in Biology. Blackie, London. 
Schalch, W. 1992 Carotenoids in the retina - a review of their possible role in preventing or limiting light damage caused by light and oxygen Free Radicals and Aging Birkhauser, Verlag, Basel, 280-298.

Schalch, W. (2001). Importance of the carotenoids lutein and zeaxanthin for the human eye. Part 1. Chim. Oggi-Chem. Today. 19, 12-15.

Seddon, J. M. (1999). Nutrition and age-related eye disease. Vitamin Nutrition Information Service. Backgrounder. 2,

Seddon, J. M., Smith and Smith (1996). A prospective study of cigarette smoking and age-related macular degeneration in women. JAMA. 276,

Sheraidah, G., Syeinmetz, R., Maguire, J., Pauleikhoff, D., Marshall, J. and Bird, A. (1993). Corelation between lipids extracted from Bruch's membrane with age. Ophthalmology. 100, 47-51.

Siegel, E., Craig, G. and Crystal, M. (1961). Distribution of $\mathrm{Zn}$ in the prostate and other organs of man. Br J Cancer. 15, 647-664.

Sies, H. (1991). Oxidative stress: from basic research to clinical application. Am J Med. 91 (Suppl), 31-37.

Sigel, H. 1983 Metal lons in Biological Systems Zinc and lts Role in Biology and Nutrition New York,

Silvestri, G. (1997). Age-related macular degeneration: Genetics and implications for detection and treatment. Mol. Med. Today. 3, 84-91.

Smith, W. and Mitchell, P. (1996). Alcohol intake and age-related maculopathy. Am. J. Ophthalmol. 122, 743-745.

Smith, W. and Mitchell, P. (1998). Family history and age-related maculopathy: the Blue Mountains Eye Study. Arch. Ophthalmol. 26, 203-206.

Snodderly, D. M., Auran, J. and Delori, F. (1984). The macular pigment II. Spatial distribution in primate retinas. Invest. Ophthalmol. Vis. Sci. 25, 674-685.

Snodderly, D. M., Handelman, G. J. and Adler, A. J. (1991). Distribution of individual macular pigment carotenoids in central retinal of macaque and squirrel monkeys. Invest Ophthalmol Vis Sci. 32, 268-279.

Solomons, M. (1979). On the assessment of zinc and copper nutriture in man. Am J Clin Nutr. 32, 856-871.

Solomons, N. and Russell, R. (1980). The interaction of vitamin A and zinc: implications for human nutrition. Am J Clin Nut. 33, 2031-2040. 
Sommerburg, O., Keunen, J. E., Bird, A. C. and van Kuijk, F. J. (1998). Fruits and vegetables that are sources for lutein and zeaxanthin: the macular pigment in human eyes. Br. J. Ophthalmol. 82, 907-910.

Stainer, L., A; Eperjesi, F (2002). Literature review of randomised controlled trials $(R C T)$ investigating the effects of nutritional supplements on agerelated eye disease. Unpublished report. Alcon.

Stone, E., Nichols, B., Kimura, A. and Weingeist, T. (1994). Clinical features of a Stargardt-like dominant progressive macular dystrophy with genetic linkage to chromosome 6q. Arch. Ophthalmol. 112, 765-772.

Stone, E., Nichols, B. and Streb, L. (1992). Genetic linkage of vitelliform macular degeneration (Best's disease) to chromosome 11 q13. Nat. Genet. 1, 246-250.

Stur, M., Tittl, M., Reitner, A. and Meisinger, V. (1996). Oral zinc and the second eye in age-related macular degeneration. Invest. Ophthalmol. Vis. Sci. 37, 1225-1235.

Swanson, A. and Truesdale, A. (1971). Elemental analysis of normal and caractous human lens tissue. Biochem Biophys Res Commun. 45, 14881496.

Tamakoshi, A., Yuzawa, M., Matsui, M., Uyama, M., Fujiwara, N. K. and Ohno, Y. (1997). Smoking and neovascular form of age-related macular degeneration in late middle aged males: findings from a case- control study in Japan. British Journal of Ophthalmology. 81, 901-904.

Taylor, H. R., Tikellis, G., Robman, L. D., McCarty, C. A. and McNeil, J. J. (2002). Vitamin E supplementation and macular degeneration: randomised controlled trial. Br. Med. J. 325, 11.

Teikari, J. M., Laatikainen, L., Virtamo, J., Haukka, J., Rautalahti, M., Liesto, K., Albanes, D., Taylor, P. and Heinonen, O. P. (1998). Six-year supplementation with alpha-tocopherol and beta- carotene and agerelated maculopathy. Acta Ophthalmol. Scand. 76, 224-229.

The AREDS Research Group (2001). A randomized, placebo-controlled, clinical trial of high-dose supplementation with vitamins $\mathrm{C}$ and $\mathrm{E}$, beta carotene, and zinc for age-related macular degeneration and vision loss - AREDS Report No. 8. Arch. Ophthalmol. 119, 1417-1436.

The ATBC Cancer Prevention Study Group (1994). The effect of vitamin E and beta-carotene on the incidence of lung cancer and other cancers in male smokers. New Engl J Med. 330, 1029-1035. 
Turnland, J., Costa, F. and Fargen, S. (1981). Zinc, copper and iron balance in elderly men. Am J Clin Nutr. 34, 2641-2647.

Ujiie, M. (1979). Studies on metabolism of trace metals in aqueous humour, ocular tissues and other organ tissues of albino rabbit. Acta Soc Ophthal. 83, 2149-2157.

Urbach, C., Hickman, K. and Harris, P. (1951). Effect of individual vitamins A, C, $E$ and carotene administered at high levels and their concentration in the blood. Exp. Med. Surg. 10, 7-20.

Van der Hagen, A., Yolton, D., Kaminski, M. and Yolton, R. (1993). Free radicals and antioxidant supplementation: a review of their roles in age related macular degeneration. J Am Optom Assoc. 64, 871-878.

Verhoeff, F. and Grossman, H. (1937). Pathogenesis of disciform degeneration of the macula. Arch. Ophthalmol. 18, 561-585.

Vinding, T. (1995). Age-related macular degeneration. Acta Ophthalmol. Scand. 217, 1-32.

Vingerling, J. R., Hofman, A., Grobbee, D. E. and deJong, P. (1996). Agerelated macular degeneration and smoking - The Rotterdam study. Arch. Ophthalmol. 114, 1193-1196.

Vitale, S., West, S. and Hallfrisch, J. (1993). Plasma antioxidants and risk of cortical and nuclear cataract. Epidemiology. 43, 195-203.

Wagner, P. (1985). Zinc nutriture in the elderly. Geriatrics. 40, 111-125.

Wagner, P., Jernigan, J. and Bailey, L. (1983). Zinc nutriture and cell-mediated immunity in the aged. Int $J$ Vitam Nutr Res. 53, 94-101.

Wald, G. (1945). Human vision and the spectrum. Science. 101, 653-658.

Werner, J., Donnelly, S. and Kliegl, R. (1987). Aging and human macular pigment density: appended with translations from the work of Max Schultze and Ewald Hering. Vision Res. 27, 257-268.

West, S., Vitale, S., Hallfrisch, J., Munoz, B., Muller, D., Bressler, S. and Bressler, N. M. (1994). Are Antioxidants or Supplements Protective for Age-Related Macular Degeneration. Arch. Ophthalmol. 112, 222-227.

Williams, H., Fenna, D. and MacBeth, R. (1971). Alpha-tocopherol in the treatment of intermittent claudication. Surg. Gynecol. Obstet. 132(4), 662-666. 
Zhang, K., Bither, P. and Park, R. (1994). A dominant Stargardt's macular dystrophy locus maps to chromosome 13q34. Arch. Ophthalmol. 112, 759-764. 


\section{Tables}

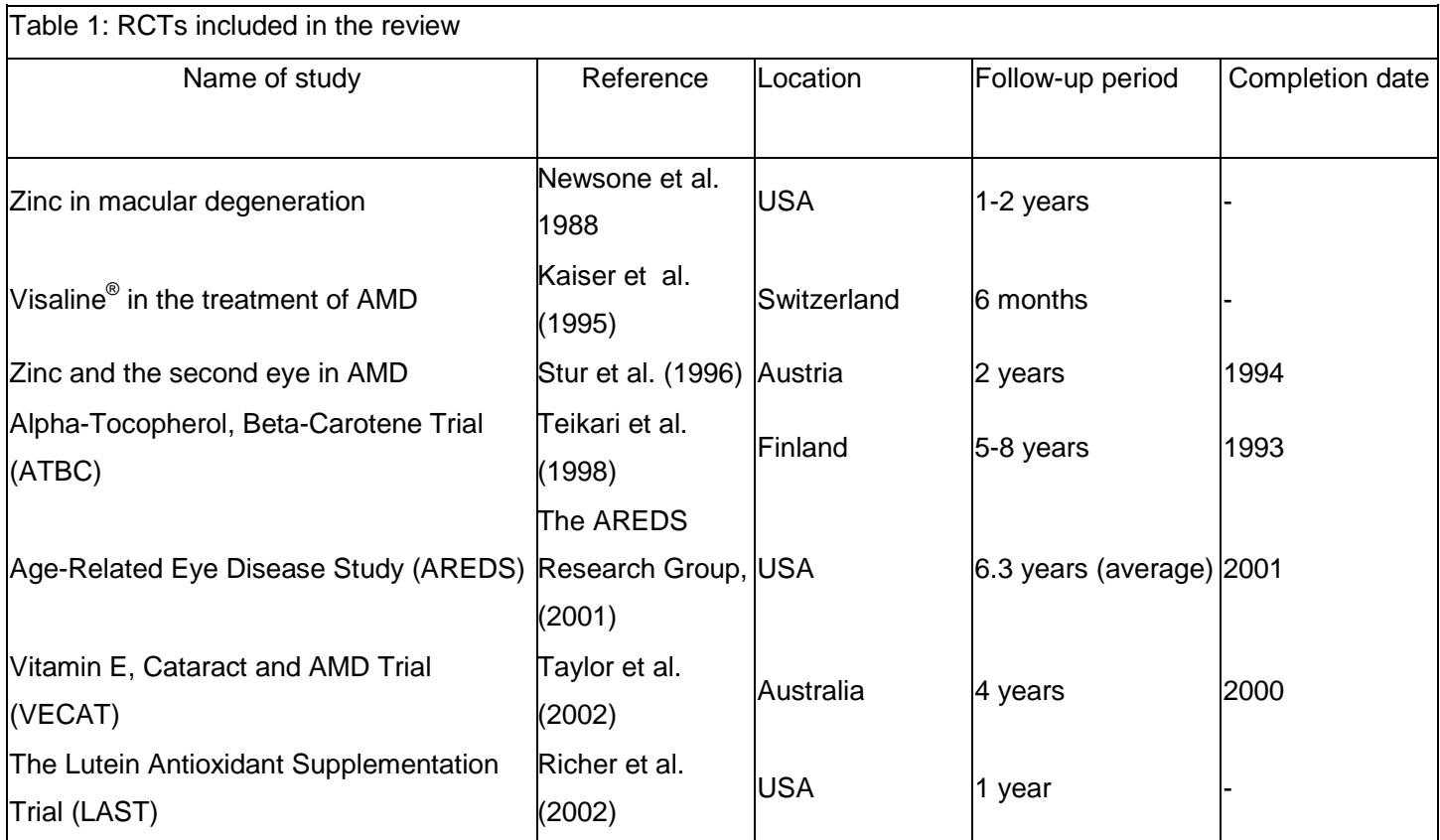

Table 2: Nutrients included in RCT formulations

\begin{tabular}{|c|c|c|}
\hline TRIAL & NUTRIENTS INCLUDED & $\begin{array}{l}\text { AMOUNT } \\
(\mathrm{mg})\end{array}$ \\
\hline Zinc in macular degeneration & Zinc & 200 \\
\hline \multirow{4}{*}{ Visaline ${ }^{\circledR}$} & Vitamin C & 200 \\
\hline & Vitamin E & 40 \\
\hline & Beta-carotene & 40 \\
\hline & Buphenine & $1.5^{*}$ \\
\hline \multirow[t]{2}{*}{ Zinc and the second eye in ARMD } & Zinc & 200 \\
\hline & Vitamin $\mathrm{E}$ & 50 \\
\hline ATBC & Beta-carotene & 20 \\
\hline \multirow{5}{*}{ AREDS } & Vitamin C & 500 \\
\hline & Vitamin E & 273 \\
\hline & Beta-carotene & 15 \\
\hline & Zinc & 80 \\
\hline & Copper & 2 \\
\hline VECAT & Vitamin E & 335 \\
\hline Lutein Antioxidant & Lutein & 10 \\
\hline Supplementation Trial & Lutein/antioxidants (not specified) & 10 \\
\hline \multicolumn{3}{|c|}{$\begin{array}{l}\text { * Buphenine is not a nutrient but a beta-adrenergic stimulant, which increases } \\
\text { peripheral blood flow, mainly by acting directly on arteries and arterioles of } \\
\text { skeletal muscle. }\end{array}$} \\
\hline
\end{tabular}




\begin{tabular}{|l|l|l|l|l|}
\hline \multicolumn{4}{|l|}{ Table 3: Recommended Daily Allowances (RDA) (mg) } \\
\hline & Male & Female & Male Smoker & Female Smoker \\
\hline Vitamin C & 90 & 75 & 125 & 110 \\
Vitamin E & 15 & 15 & 15 & 15 \\
Zinc & 15 & 15 & 15 & 15 \\
Lutein & 6 & 6 & 6 & 6 \\
\hline
\end{tabular}

\begin{tabular}{|c|c|}
\hline Trial & $R$ value \\
\hline Visaline $^{\circledR}$ & 88.5 \\
\hline $\begin{array}{l}\text { Zinc in the second eye } \\
\text { (Stur et al. 1996) }\end{array}$ & 16.1 \\
\hline $\begin{array}{l}\text { Zinc in macular degeneration } \\
\text { (Newsome et al. 1988) }\end{array}$ & 71.9 \\
\hline
\end{tabular}

\begin{tabular}{|c|c|}
\hline Category & Definition \\
\hline 1 & $\begin{array}{l}\text { No drusen or drusen }<63 \mu \mathrm{m} \text { with an area }<125 \mu \mathrm{m} \\
\text { diameter circle and no pigment abnormalities }\end{array}$ \\
\hline 2 & $\begin{array}{l}\text { Small drusen }(<63 \mu m) \text { with an area } \leq 125 \mu m \\
\text { diameter circle with possible pigment } \\
\text { abnormalities but no geographical atrophy } \\
\text { OR no drusen if pigment abnormalities are } \\
\text { present }\end{array}$ \\
\hline $3 a$ & $\begin{array}{l}\text { Intermediate drusen }(\geq 63<125 \mu \mathrm{m}) \text { with } \geq 360 \mu \mathrm{m} \\
\text { diameter circle if soft indistinct drusen are } \\
\text { present, } \geq 656 \mu \mathrm{m} \text { diameter circle if soft indistinct } \\
\text { drusen are absent. Pigment abnormalities could } \\
\text { be absent or present but geographical atrophy } \\
\text { was absent } \\
\text { OR large } \geq 125 \mu \mathrm{m} \text { drusen }\end{array}$ \\
\hline & $\begin{array}{l}\text { OR no drusen required if non-central geographic } \\
\text { atrophy is present }\end{array}$ \\
\hline $3 b$ & $\begin{array}{l}\text { First eye same as category } 3 a . V A<20 / 32 \text { in the } \\
\text { second eye not due to AMD }\end{array}$ \\
\hline $4 a$ & $\begin{array}{l}\text { First eye same as category } 1,2 \text { or } 3 a \text { with } \\
\text { advanced AMD in the second eye }\end{array}$ \\
\hline $4 b$ & $\begin{array}{l}\text { First eye same as category } 1,2 \text {, or } 3 a \text { with VA }< \\
20 / 32 \text { in the second eye due to AMD but not } \\
\text { presenting advanced AMD. }\end{array}$ \\
\hline
\end{tabular}




\begin{tabular}{|l|l|}
\hline \multicolumn{2}{|l|}{ Table 6: Probability of AMD event for each category } \\
\hline AMD category & Probability of AMD event at year 5 \\
\hline 2 & $1.3 \%$ \\
3 & $18.3 \%$ \\
4 & $42.9 \%$ \\
\hline
\end{tabular}

\begin{tabular}{|l|l|}
\hline Table 7: Probability of AMD event by treatment arm \\
\hline Treatment arm & Probability of AMD event at year 5 \\
\hline Placebo & $27.8 \%$ \\
Antioxidants & $22.6 \%$ \\
Zinc & $21.6 \%$ \\
Zinc + antioxidants & $20.2 \%$ \\
\hline
\end{tabular}

\begin{tabular}{|l|l|}
\hline Table 8: Probability of VA event by treatment arm \\
\hline Treatment arm & Probability of VA event at year 5 \\
\hline Placebo & $29.1 \%$ \\
Antioxidants & $25.9 \%$ \\
Zinc & $25.5 \%$ \\
Zinc + antioxidants & $23.1 \%$ \\
\hline
\end{tabular}

\begin{tabular}{|l|l|}
\hline $\begin{array}{l}\text { Table 9: Increase in median serum levels from baseline to } \\
\text { year } 1 \text { in the antioxidants arm }\end{array}$ \\
\hline Antioxidant & $\%$ increase \\
\hline Vitamin C & 25 \\
\hline $\begin{array}{l}\text { Vitamin E-cholesterol } \\
\text { Ratio }\end{array}$ & 82 \\
\hline Beta-carotene & 485 \\
\hline
\end{tabular}




\begin{tabular}{|l|l|l|}
\hline \multicolumn{3}{|l|}{$\begin{array}{l}\text { Table 10: Changes in median serum levels in the placebo } \\
\text { and zinc arms from baseline to year 5 }\end{array}$} \\
\hline \multirow{2}{*}{ Antioxidant } & \multicolumn{2}{|c|}{$\%$ change } \\
\cline { 2 - 3 } & Placebo Zinc \\
\hline Vitamin C & -7 & -12 \\
\hline $\begin{array}{l}\text { Vitamin E-cholesterol } \\
\text { Ratio }\end{array}$ & +6 & +6 \\
\hline Beta-carotene & +4 & 0 \\
\hline
\end{tabular}

\begin{tabular}{|l|l|l|}
\hline \multicolumn{3}{|l|}{ Table 11: VECAT early AMD grading system } \\
\hline Feature & Grading of photographs & $\begin{array}{l}\text { Clinical } \\
\text { grading }\end{array}$ \\
\hline $\begin{array}{l}\text { Early AMD } \\
1\end{array}$ & $\begin{array}{l}\text { Soft intermediate or soft distinct or } \\
\text { soft indistinct or pigment changes } \\
\text { (hyperpigmentation or } \\
\text { hypopigmentation) }\end{array}$ & $\begin{array}{l}\text { Not } \\
\text { applicable }\end{array}$ \\
\hline Early AMD & $\begin{array}{l}\text { Soft intermediate or soft distinct or } \\
\text { soft indistinct and pigment } \\
\text { changes (hyperpigmentation or } \\
\text { hypopigmentation) }\end{array}$ & $\begin{array}{l}\text { Not } \\
\text { applicable }\end{array}$ \\
\hline $\begin{array}{l}\text { Early AMD } \\
3\end{array}$ & $\begin{array}{l}\text { Soft distinct or soft indistinct or } \\
\text { pigment changes } \\
\text { (hyperpigmentation or } \\
\text { hypopigmentation) }\end{array}$ & $\begin{array}{l}\text { Large/soft } \\
\text { drusen or } \\
\text { non- } \\
\text { geographical } \\
\text { RPE atrophy }\end{array}$ \\
\hline Early AMD & $\begin{array}{l}\text { Soft distinct or soft indistinct and } \\
\text { pigment changes } \\
\text { (hyperpigmentation or } \\
\text { hypopigmentation) }\end{array}$ & $\begin{array}{l}\text { Large/soft } \\
\text { drusen and } \\
\text { non- } \\
\text { geographical } \\
\text { RPE atrophy }\end{array}$ \\
\hline
\end{tabular}




\begin{tabular}{|l|l|l|}
\hline \multicolumn{2}{|l|}{ Table 12: Summary of RCT results } & Effect Seen \\
\hline RCT & Nutrients Included & Positive result in \\
AREDS & Vit C, Vit E, beta-carotene, zinc & combination \\
ATBC & Vit E, beta-carotene & No effect \\
VECAT & Vit E & No effect \\
Visaline ${ }^{(\circledast)}$ in the treatment of AMD & Vit C, Vit E, beta-carotene, buphenine & No effect \\
Zinc in macular degeneration & Zinc & Positive effect \\
Zinc and the second eye in AMD & Zinc & No effect \\
LAST & Lutein, antioxidants & Positive effect \\
\hline Table 9: Summary of RCT results & \\
\hline
\end{tabular}

\section{Abbreviated title}

AMD and nutrition - a review of randomised controlled trials 


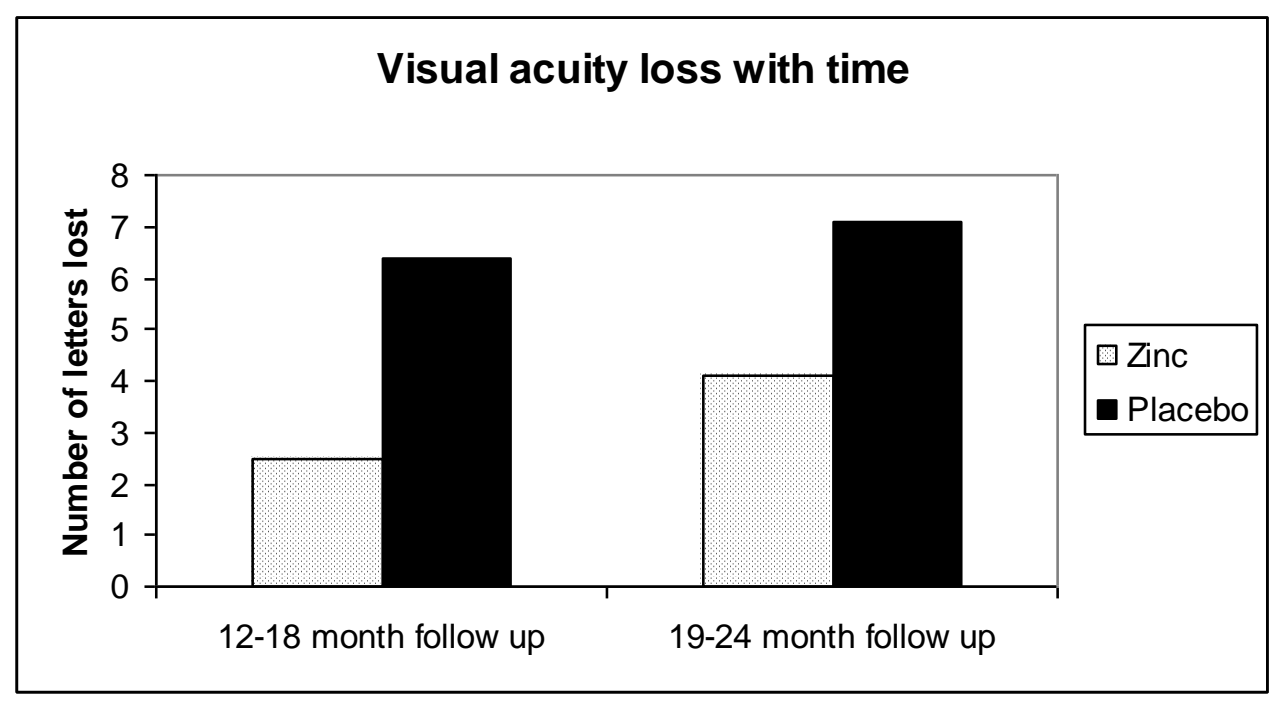

Figure 1

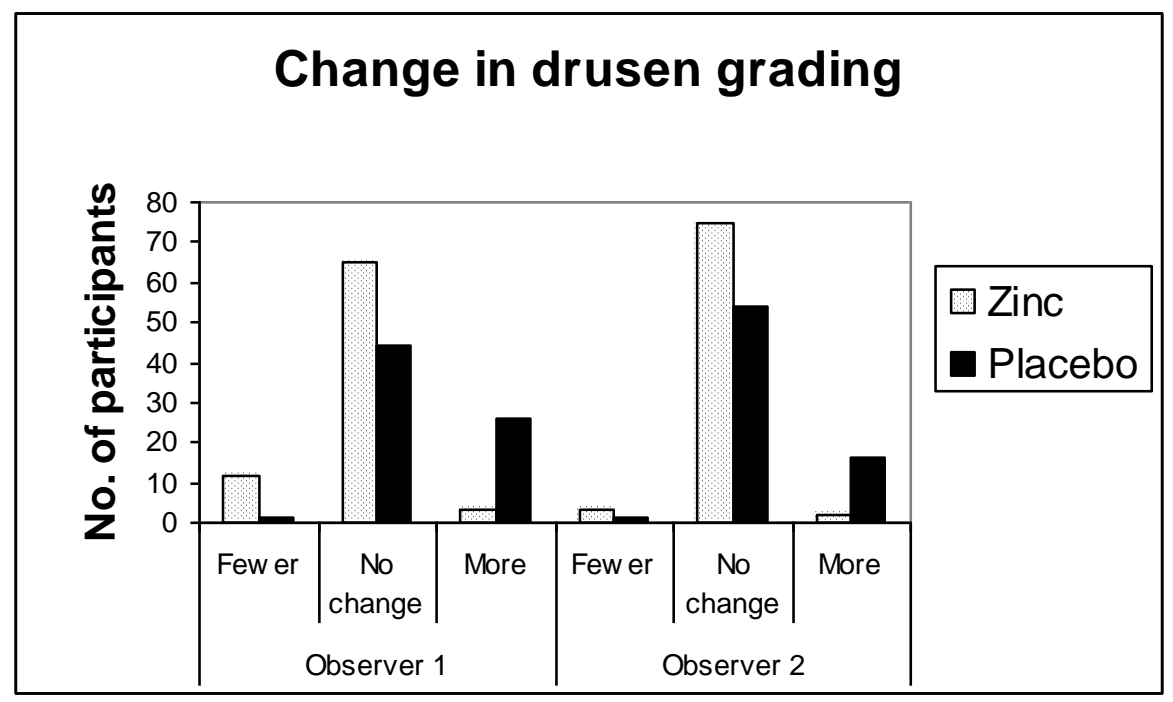

Figure 2

Page 56 of 59 


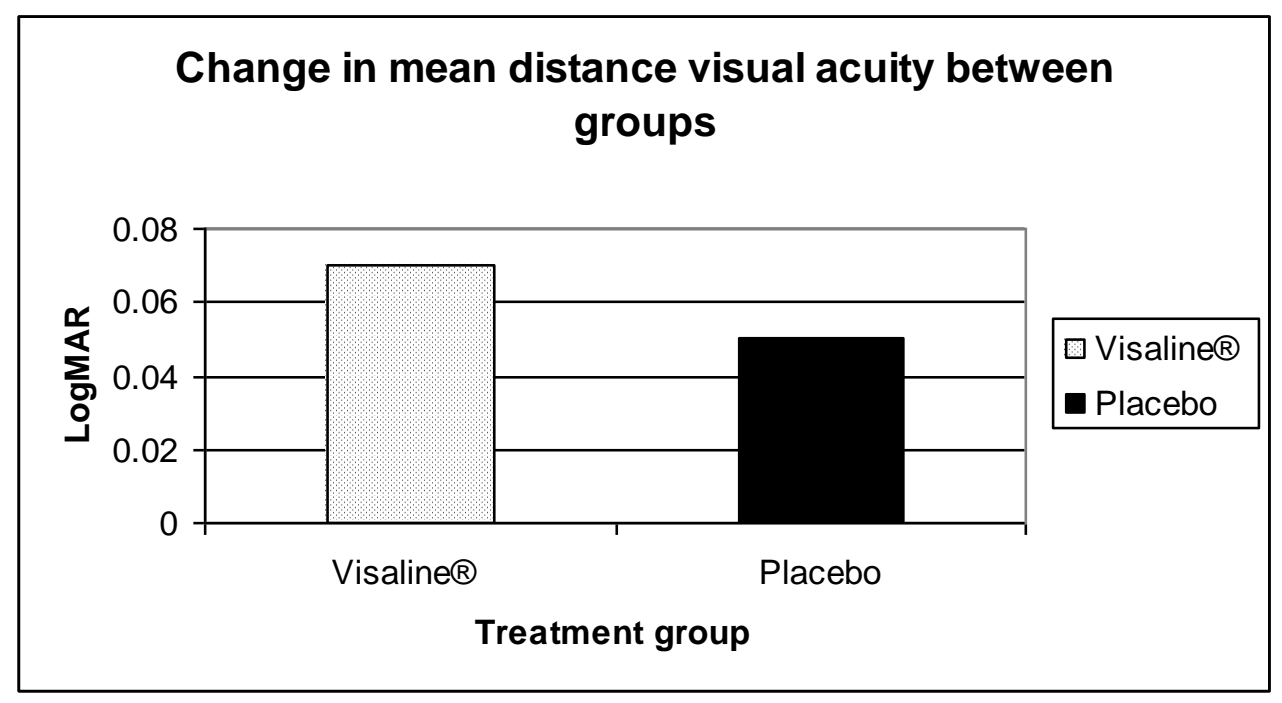

Figure 3

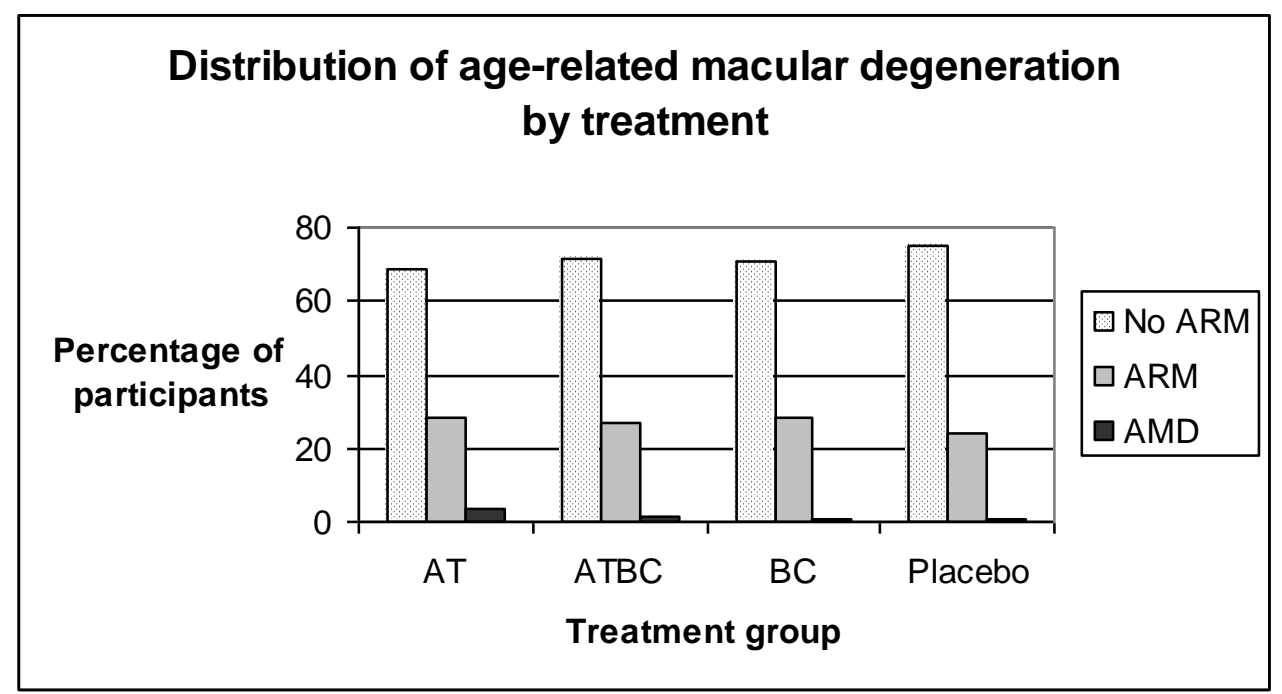

Figure 4 


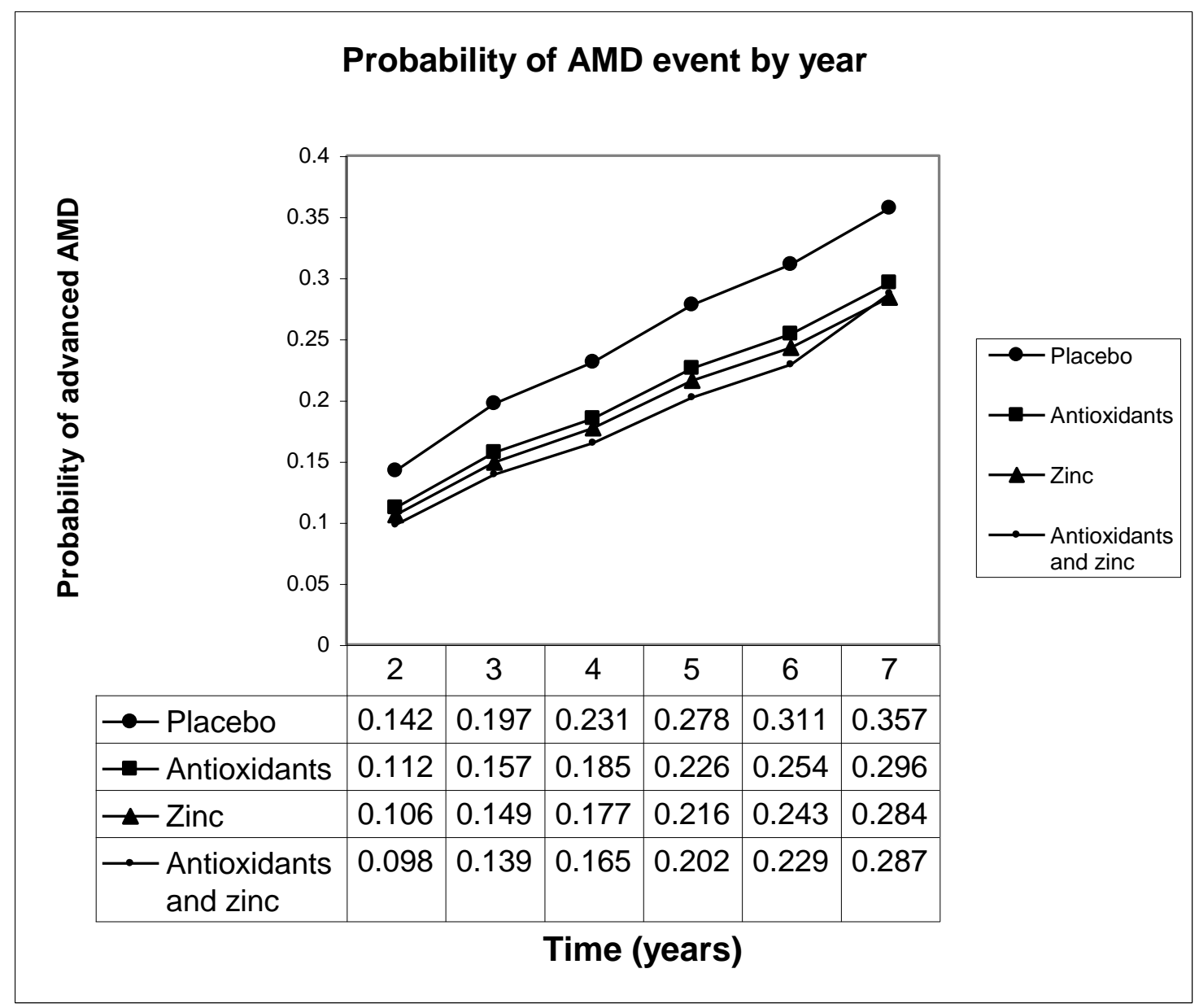

Figure 5 


\section{Captions to figures}

Figure 1: Visual acuity loss with time in the Newsome et al. (1988) study

Figure 2: Change in drusen grading by observer in the Newsome et al. (1988) study

Figure 3: Change in mean distance visual acuity between treatment groups in the Visaline ${ }^{\circledR}$ study (Kaiser et al. 1995)

Figure 4: Distribution of ARM/AMD by treatment group in the ATBC Study (Teikari et al. 1998)

Figure 5: Probability of AMD event at year 5 by treatment arm (Archives of Ophthalmology (2001) 119, 1417-1436) 